\title{
Anesthesia for minimally invasive cardiac surgery: is it still a place for opioids?
}

\author{
Despoina G. Sarridou $^{1,2}$, Afroditi K. Boutou ${ }^{3}$, Sophia Anastasia Mouratoglou ${ }^{4}$ \\ ${ }^{1}$ Department of Cardiothoracic and Vascular Anesthesia, General Hospital "G. Papanikolaou”, Thessaloniki, Greece; ${ }^{2}$ Department of Anesthetics, \\ Guy's and St Thomas' NHS Foundation Trust, London, UK; ${ }^{3}$ Department of Respiratory Medicine, G. Papanikolaou Hospital, Thessaloniki, \\ Greece; ${ }^{4}$ Department of Anesthesiology and Intensive Care, Intensive Care Unit, AHEPA University Hospital of Thessaloniki, Aristotle University \\ of Thessaloniki, Thessaloniki, Greece \\ Correspondence to: Despoina G. Sarridou, MD. Anesthesiologist, Department of Cardiothoracic and Vascular Anesthesia, General Hospital "G. \\ Papanikolaou", Chortiatis, 57010 Thessaloniki, Greece. Email: dodasarri@yahoo.gr. \\ Comment on: White A, Patvardhan C, Falter F. Anesthesia for minimally invasive cardiac surgery. J Thorac Dis 2021;13:1886-98.
}

Submitted Jun 01, 2021. Accepted for publication Jul 02, 2021.

doi: $10.21037 /$ jtd-21-910

View this article at: https://dx.doi.org/10.21037/jtd-21-910

With great interest we read the very thorough manuscript of White et al. reviewing the highly specialized topic of anesthetic considerations and analgesic strategies for minimal invasive cardiac surgery (MICS) (1). Pain management remains a big challenge for the cardiothoracic anesthesiologist and even though the article stresses the significancy of regional techniques, there is no mention to the traditional intravenous opioid use that kept us going and still does all these years. Undoubtedly, the opioid side effects impairing early rehabilitation is the major fear; however low dose fentanyl patients control analgesia with adjuncts or not (e.g., ketamine), while this approach lacks severe side effects and studies have shown that it cannot be considered inferior to thoracic epidural anesthesia for thoracotomy performed for video-assisted thoracoscopic surgery (VATS), with all its higher risks and limitation of heparinization (2). Moreover, the pain after MICS resembles the one after mini thoracotomy and VATS procedures. Studies have shown that the analgesic efficacy of patient-controlled analgesia is comparable to the one after paravertebral block and thoracic epidural and perhaps it is a sufficient alternative (3). Alfentanil continuous infusion is also a quite effective and trusted option in minimally invasive direct coronary artery bypass.

Ultrasound guided regional continuous techniques with catheters are supreme to single shot local anesthetic blocks. Erector spinae plane block can be performed easily in lateral or sitting position, the anatomic area where the catheter is placed, perhaps the less sinister for complications and it enhances early recovery and rehabilitation with opioid sparing side effects in cardiac surgical patients (4). It cannot be considered inferior to the paravertebral block in terms of efficacy and lacks the risk of sympathetic blockade (5). Serratus plane block is also quite useful; however, more studies in cardiac surgical patients are needed in order to elucidate better the role of regional techniques.

In conclusion, anesthesiologists should balance the risk and the benefits and choose an individualized analgesia plan based on their competencies, familiarity with different regional techniques and different opioid regimes always tailored on the patient's characteristics and requirements and the nature of the surgical procedure.

\section{Acknowledgments}

Funding: None.

\section{Footnote}

Provenance and Peer Review: This article was a standard submission to the journal. The article did not undergo external peer review.

Conflicts of Interest: All authors have completed the ICMJE uniform disclosure form (available at https://dx.doi. org/10.21037/jtd-21-910). The authors have no conflicts of interest to declare. 
Ethical Statement: The authors are accountable for all aspects of the work in ensuring that questions related to the accuracy or integrity of any part of the work are appropriately investigated and resolved.

Open Access Statement: This is an Open Access article distributed in accordance with the Creative Commons Attribution-NonCommercial-NoDerivs 4.0 International License (CC BY-NC-ND 4.0), which permits the noncommercial replication and distribution of the article with the strict proviso that no changes or edits are made and the original work is properly cited (including links to both the formal publication through the relevant DOI and the license). See: https://creativecommons.org/licenses/by-nc-nd/4.0/.

\section{References}

1. White A, Patvardhan C, Falter F. Anesthesia for minimally invasive cardiac surgery. J Thorac Dis 2021;13:1886-98.

2. Tseng WC, Lin WL, Lai HC, et al. Fentanyl-based intravenous patient-controlled analgesia with low dose

Cite this article as: Sarridou DG, Boutou AK, Mouratoglou SA. Anesthesia for minimally invasive cardiac surgery: is it still a place for opioids? J Thorac Dis 2021;13(8):5111-5112. doi: 10.21037/jtd-21-910 of ketamine is not inferior to thoracic epidural analgesia for acute post-thoracotomy pain following video-assisted thoracic surgery: A randomized controlled study. Medicine (Baltimore) 2019;98:e16403.

3. Haager B, Schmid D, Eschbach J, et al. Regional versus systemic analgesia in video-assisted thoracoscopic lobectomy: a retrospective analysis. BMC Anesthesiol 2019;19:183.

4. Macaire P, Ho N, Nguyen T, et al. Ultrasound-Guided Continuous Thoracic Erector Spinae Plane Block Within an Enhanced Recovery Program Is Associated with Decreased Opioid Consumption and Improved Patient Postoperative Rehabilitation After Open Cardiac Surgery-A Patient-Matched, Controlled Before-and-After Study. J Cardiothorac Vasc Anesth 2019;33:1659-67.

5. Taketa Y, Irisawa Y, Fujitani T. Comparison of ultrasoundguided erector spinae plane block and thoracic paravertebral block for postoperative analgesia after videoassisted thoracic surgery: a randomized controlled noninferiority clinical trial. Reg Anesth Pain Med 2019. [Epub ahead of print]. doi: 10.1136/rapm-2019-100827. 